\title{
Antiproliferative and pro-apoptotic effects of quercetin on human pancreatic carcinoma cell lines EPP85-181P and EPP85-181RDB
}

\author{
Sylwia Borska ${ }^{1}$, Malgorzata Drag-Zalesinska ${ }^{1}$, Teresa Wysocka ${ }^{1}$, Miroslaw Sopel ${ }^{1}$, \\ Malgorzata Dumanska1, Maciej Zabel ${ }^{1,2}$ and Piotr Dziegiel ${ }^{1,2,3}$
}

\author{
${ }^{1}$ Department of Histology and Embryology, Medical University, Wroclaw, Poland, \\ ${ }^{2}$ Department of Histology and Embryology, University of Medical Sciences, Poznan, Poland, \\ ${ }^{3}$ Lower Silesian Centre of Oncology, Wroclaw, Poland
}

\begin{abstract}
Polyphenols are present in several edible plants and for many years induce high interest mainly due to their antioxidative and anti-inflammatory influence. At present, numerous studies are conducted on antineoplastic effects of the compounds. One of most effective biopolyphenols involves the flavonol quercetin. Our studies aimed at evaluation of antiproliferative and pro-apoptotic effects of quercetin alone and in combinations with daunorubicin on cells of human pancreatic carcinoma lines. The experiments were conducted on two cell lines, sensitive to daunorubicin EPP85-181P line, and its resistant variant EPP85-181RDB. Effect of studied substances on cell proliferation was detected using sulphorhodamine B (SRB) protein staining method. Apoptotic damage was estimated using comet and TUNEL techniques. Our data demonstrated that quercetin exerted cytotoxic action on cells of the both neoplastic cell lines in concentration-dependent manner. In the case of EPP85-181RDB cell line, quercetin seemed to sensitize resistant cells to daunorubicin. In parallel, the effect of both substances on the sensitive cell line was synergistic. Results of the studies confirmed that quercetin may probably break resistance of neoplastic cells to chemotherapy. On the other side, studied flavonol augmented action of cytostatic drug in case of sensitive tumour cells what suggest, that it might allow to decrease dosage of cytostatic drugs and reduce negative side effects of the treatment.
\end{abstract}

Key words: quercetin, daunorubicin, antiproliferative effect, apoptosis, human pancreatic carcinoma cell lines

\section{Introduction}

Quercetin (Q) belongs to the vast group of flavonoids present in several edible plants, particularly in onion, Italian cabbage, apples, and grapes. For the last decades $\mathrm{Q}$ has been known as a strong antioxidant, an anti-inflammatory agent, a vaso-dilatatory compound, and an agent which decreases blood pressure and inhibits aggregation of blood platelets [1-3]. Also on multiple occasions Q was found to exert antineoplastic effects on all stages of carcinogenesis $[1,2,4,5]$. However, mechanisms of $\mathrm{Q}$ action have not been fully recognised and continue to provide topic for intense in

Correspondence: S. Borska, Dept. Histology and Embryology, Medical University, Chalubinskiego 6a, 50-368 Wroclaw, Poland; tel.: $(+4871) 7841683$, fax.: $(+4871) 7840082$,

e-mail: borska@hist.am.wroc.pl vivo and in vitro studies. Several of them showed that $\mathrm{Q}$ inhibit proliferation and induce apoptosis in cells of many tumours, including cancers of breast, lungs, colon or gliomas [2,5-11]. In contrast, in normal cells $Q$ was noted to exert an anti-apoptotic effect $[12,13]$.

Anthracyclins, including daunorubicin (DB), belong to cytostatic antibiotics frequently applied in chemotherapy. Cytotoxicity of DB reflects mainly its direct effect on DNA and enzymes such as topoisomerase II (Topo II), generation of high amounts of free radicals and damage to cell membrane. This results in a disturbed replication, transcription and cellular homeostasis, leading to apoptotic death of the cell. Despite its high efficacy, application of DB is restricted due to the pronounced cardio-, nephro- and myelotoxicity. Moreover, the frequently appearing multidrug resistance (MDR) causes that the therapy remains without the expected result $[14,15]$. 
The antineoplastic properties of Q are linked mainly with its effect on expression of some oncogens, cell cycle-suppressory genes and their products. Q affects directly various type kinases, e.g., protein kinase $\mathrm{C}, \mathrm{PI}$ $3 \mathrm{~K}, \mathrm{MAPK}, \mathrm{ERK}, \mathrm{CDK}$ and their respective metabolic pathways, which play a significant role in carcinogenesis [16-21]. The studies on effects of carcinogens on normal cells in presence of $\mathrm{Q}$, demonstrated also its antioxidant properties and a protective role against mutagenesis in healthy tissues [2,22-24]. $\mathrm{Q}$ exerts influence on expression of several genes and proteins, engaged in control of cell cycle, cell differentiation, programmed cell death, processes of cells adhesion and interactions $[7,8,25]$. Apart from the direct pro-apoptotic effect on neoplastic cells, administration of some polyphenols might be useful in overcoming MDR phenomenon acting as chemo- and photosensitizers. Results of such studies are very promising [26-29].

Considering the above data, our study aimed at examining if $\mathrm{Q}$ is effective cytotoxic agent toward selected cell lines of pancreatic carcinoma and if it supports pro-apoptotic action of DB.

\section{Material and methods}

Cell lines and conditions of culture. The in vitro studies were conducted on cell lines of human pancreatic carcinoma sensitive and resistant to DB, EPP85-181P and EPP85-181RDB respectively. Both cell lines were obtained from Institute of Pathology, University Hospital Charite in Berlin where they had been established by in vitro exposure to DB (Farmitalia Carlo Erba, Freiburg, Germany). The cell cultures were grown in modified Leibovitz $\mathrm{L} 15$ medium in a humidifed incubator at $37^{\circ} \mathrm{C}$ in an atmosphere of $5 \% \mathrm{CO}_{2}$. The cell culture followed the description of Lage et al. [30].

Proliferation tests. All proliferation tests were based on a colorimetric technique using sulphorhodamine B (SRB) dye, as described by Skehan et al. [31]. Substances added to the cultures, $\mathrm{Q}$ and $\mathrm{DB}$, and the remaining reagents were purchased from SIGMA (Germany). The absorbance was read at the wavelength of $564 \mathrm{~nm}$ using a microplate-reader (ELX-800, BIO-TEK, USA).

On the basis of preliminary tests (calibration tests for individual lines and a cytotoxic test for the two examined compounds) the final experiment was performed, aimed to detect cytotoxic effect of DB and Q, used separately or together in various combinations of concentrations, on EPP85-181P and EPP85-181RDB cell lines. The cells were transferred to $96-$ well plates, 800 cells per well. Following $24 \mathrm{~h}$ of culture, the drugs were added in various concentrations and combinations (12 repetitions) as follow:

1) Q: Q3 $(3 \mu \mathrm{M})$, Q6 $(6 \mu \mathrm{M})$ and Q12 $(12 \mu \mathrm{M})$;

2) DB: $K 2(0.43 \mu \mathrm{M}$, the concentration corresponding to the therapeutic dose of DB in patient's blood $2 \mathrm{~h}$ after administration of the drug, for DB it amounted to $0.25 \mathrm{mg} / \mathrm{ml}), \mathrm{K} 1(0.043 \mu \mathrm{M})$ and $\mathrm{K} 3$ $(4.3 \mu \mathrm{M})$;

3) combinations: Q3/K1, Q3/K2, Q3/K3, Q6/K1, Q6/K2, Q6/K3, $\mathrm{Q} 12 / \mathrm{K} 1, \mathrm{Q} 12 / \mathrm{K} 2, \mathrm{Q} 12 / \mathrm{K} 3$ (the cytostatic drug was added to the culture $2 \mathrm{~h}$ after addition of $\mathrm{Q}$ );

4) control (with no drugs added).

Absorbance (optical density values, OD) was read after $72 \mathrm{~h}$ drugs exposure.
Evaluation of apoptosis. Cells of both lines were transferred to 24 -well plates, at $2 \times 10^{4}$ cells $/ \mathrm{ml}$, the tested substances were added, as in the case of proliferation tests, following $24 \mathrm{~h}$, omitting the combination with the $\mathrm{K} 3$ dose of a cytostatic drug. After $72 \mathrm{~h}$ damage to cell nuclei was detected using comet assay with neutral electrophoresis, according to the procedure of Yasuhara et al. [32]. The slides were silver-stained, as described by Cerda et al. and then analyzed under a light microscope (Olympus BX41, Japan) [33]. The proportion of damaged cell nuclei was appraised per visual field, taking into account a mean score following screening 5 fields in every slide (magnification of $200 \times$ ). In the neutral technique, routinely intact cells (lack of the typical tail, normal size of the head) were marked as 0 grade, and 4 grades of cell nucleus damage are distinguished, taking into account size of the head, length of the tail and their reciprocal ratio [32]. The obtained results were collected and categorized to 3 ranges of cell nucleus damage:

1) 0 - intact cell nuclei

2) grades 1 and 2 - intermediate damage (size of the tail $<50 \%$ )

3 ) grades 3 and 4 - apoptotic nuclei (size of the tail $>50 \%$ ).

In addition, the apoptotic cells were detected by the TUNEL technique. Following $72 \mathrm{~h}$ of incubation, cells cultured and prepared as before the comet assay tests were placed on diagnostic slides, fixed in the cold $\left(-20^{\circ} \mathrm{C}\right)$ methanol:acetone $(1: 1)$ mixture for $15 \mathrm{~min}$ at the temperature of $4^{\circ} \mathrm{C}$ and dried with a cold air. The apoptotic cell nuclei were detected using Apop Tag Peroxidase in situ Apoptosis Detection kit (INTERGEN, USA), as recommended by the manufacturer. At the terminal stage of the reaction, DAB was used as a dye and cell nuclei were counterstained with hematoxylin. The preparations were analyzed under a light microscope (Olympus BX41, Japan) using a software for computer-assisted image analysis (Analysis 3.2, Germany).

Percentage of apoptotic cell nuclei was appraised per visual field, taking into account a mean score from 3 fields for every well (magnification $\times 200)$ in every slide for 3 wells/repetitions.

Statististical analysis. The obtained results were subjected to statistical analysis using Student's t-test and taking adventage of SPSS 14 software (USA). The results were regarded statistically significant at $\mathrm{p}<0.05$.

\section{Results}

\section{Effect of $D B$ and $Q$ on cells proliferation}

\section{EPP85-181P line}

Effect of DB and Q applied separately, as compared to the control. The line of EPP85-181P was found to be sensitive to action of DB in cases of all tested doses. K1 reduced cell number by $32 \%$, K2 by $89 \%$, while K3 by $94 \%$, as compared to the control. Sensitivity of cells to Q was also evident in every applied concentration of the polyphenol. In comparison with the control, Q3 concentration decreased OD by 22\%, Q6 by $36 \%$, while Q12 by as much as $74 \%$. All differences proved to be statistically significant $(\mathrm{p}<0.001)$.

Effect of $D B / Q$ combinations in comparison with the action of $\mathbf{Q}$ alone (Fig. 1). Administration of $\mathrm{Q}$ in parallel to $\mathrm{DB}$, as compared to application of the same concentration of $\mathrm{Q}$ alone, decreased OD in all tested cases. The combinations with DB demonstrated inhibition of proliferation dependent on the dose of the cytostatic drug and the differences were statistically significant $(\mathrm{p}<0.001)$. 


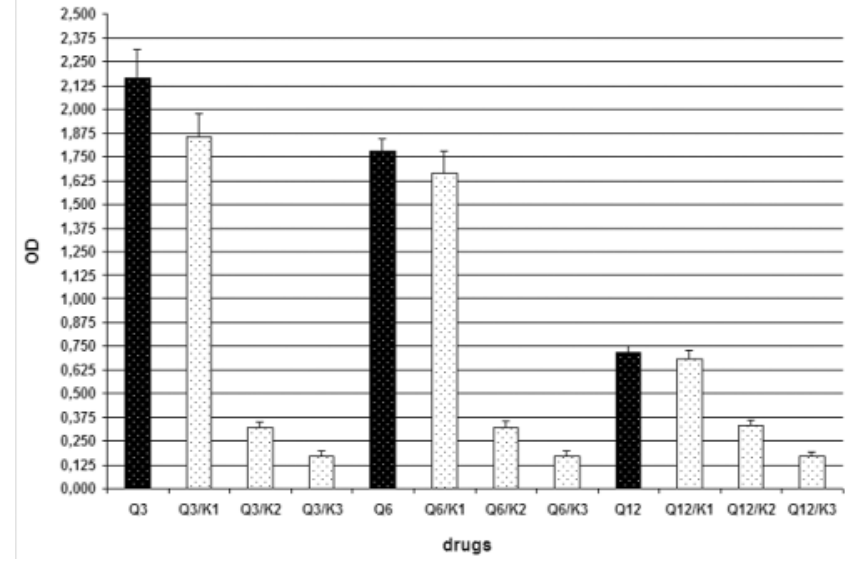

Fig. 1. Effect of administering various concentrations of $Q$ and $D B$ on optical density (OD) for cells of EPP85-181P line, $p<0.001$ for all drug combinations as compared to effect of $\mathrm{Q}$ alone.

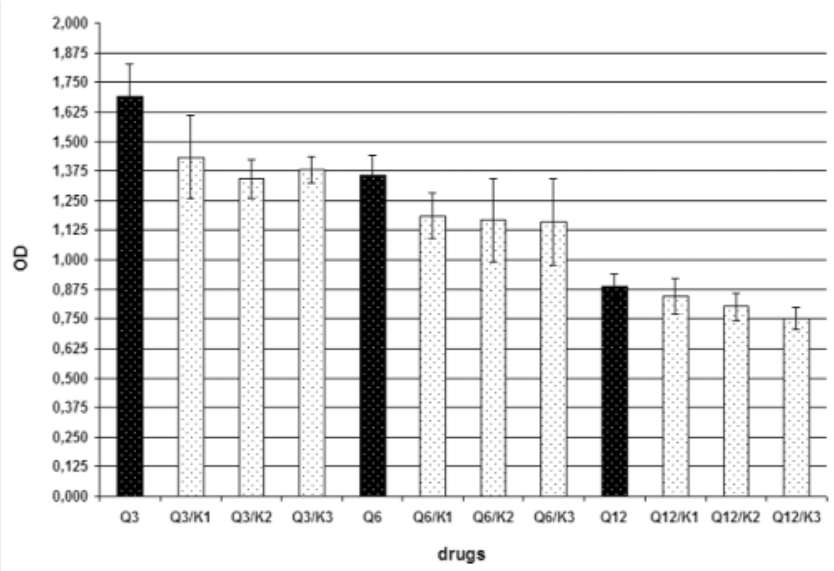

Fig. 3. Effect of administering various concentrations of $Q$ and $D B$ on optical density (OD) for cells of EPP85-181RDB line, $p<0.001$ for all drug combinations as compared to effect of $\mathrm{Q}$ alone.

Effect of $\mathrm{DB} / \mathrm{Q}$ combinations in comparison with the action of DB alone (Fig. 2). Only the combinations of Q6/K1 and Q12/K1 induced a statistically significant decrease in the cell number $(\mathrm{p}<0.001)$ as compared to the effect of the cytostatic drug alone (K1).

\section{EPP85-181RDB line}

Effect of tested substances, as compared to the control. No effect of DB on cells of the resistant line was detected, the differences in absorbance were insignificant ( $p>0,05)$. On the other hand, Q exerted effect on the studied cells in concentrations of Q6 and Q12. Following administration of Q6 OD decreased by $24 \%$, and following Q12 by $50 \%$. The differences between effects of individual doses and also between Q6 or Q12 and the control were statistically significant $(p<0,001)$. The concentration of Q3 exerted no significant effect on the proliferation ( $p>0.05)$.

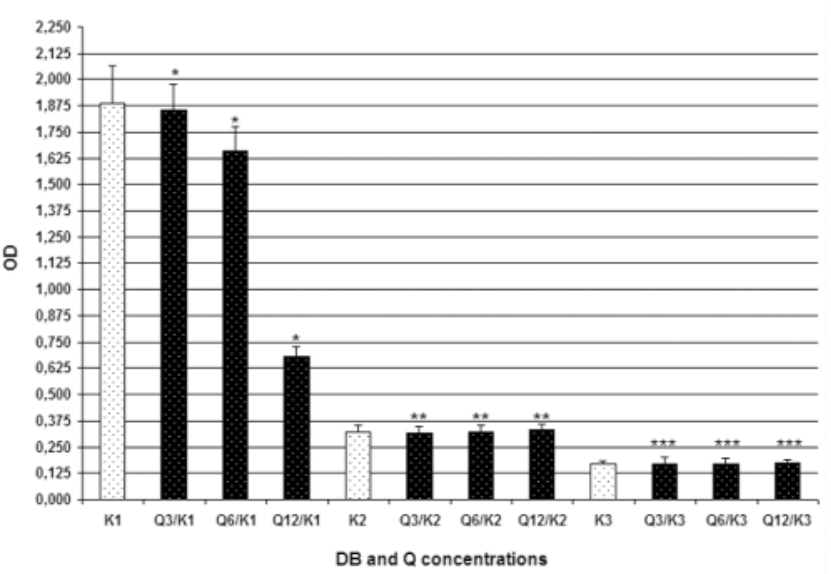

Fig. 2. Effect of administering various concentrations of $Q$ and $D B$ on optical density (OD) for cells of EPP85-181P line, ${ }^{*} \mathrm{p}<0.001$ for combinations $\mathrm{K} 1 / \mathrm{Q}$ vs $\mathrm{K} 1,{ }^{* *} \mathrm{p}<0.05$ for combinations $\mathrm{K} 2 / \mathrm{Q}$ vs $\mathrm{K} 2$, ${ }^{* * *} \mathrm{p}>0.05$ for combinations K3/Q vs K3.

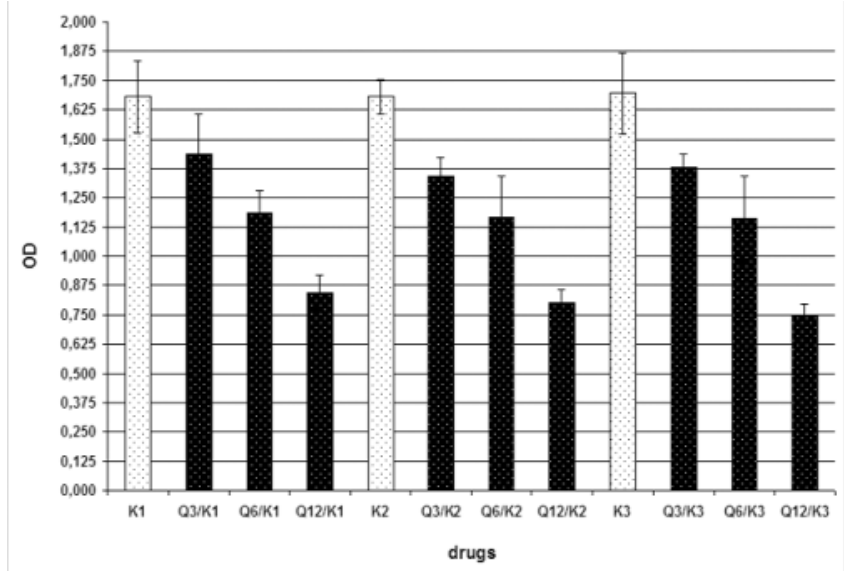

Fig. 4. Effect of administering various concentrations of $Q$ and $D B$ on optical density (OD) for cells of EPP85-181P line, $p<0.001$ for all drug combinations as compared to effect of $\mathrm{Q}$ alone.

Effect of $D B / Q$ combinations in comparison with the action of $Q$ alone (Fig. 3). Combinations of DB and $\mathrm{Q}$ in comparison with the influence of $\mathrm{Q}$ alone decreased $\mathrm{OD}$ in a statistically significant manner $(\mathrm{p}<0.001)$. Only in the case of Q12/K1 the difference was insignificant $(\mathrm{p}>0.05)$.

Effect of $D B / Q$ combinations in comparison with the action of DB alone (Fig. 4). As compared to the effect of DB, supplementation with Q resulted in an additional inhibition of proliferation in cases of any applied concentration of $\mathrm{Q}$. The differences between individual drug combinations were also statically significant $(\mathrm{p}<0.001)$.

\section{Apoptotic damage under effect of quercetin and daunorubicin}

EPP85-181P line. As demonstrated by results of the comet technique, pro-apoptotic action of $\mathrm{DB}$, as 
Table 1. Effect [\%] of Q and DB on cells of EPP85-181P (P) and EPP85-181RDB (RDB) lines, examined by the TUNEL technique.

\begin{tabular}{|l|c|c|}
\hline \multirow{2}{*}{ Sample } & $\mathrm{P}$ & $\mathrm{RDB}$ \\
\cline { 2 - 3 } & \multicolumn{2}{|c|}{$\%$ apoptotic cell nuclei } \\
\hline Control & 3 & 0 \\
\hline K1 & 15 & 0 \\
\hline K2 & 81 & 0 \\
\hline K3 & 90 & 0 \\
\hline Q3 & 13 & 0 \\
\hline Q3/K1 & 64 & 1 \\
\hline Q3/K2 & 80 & 2 \\
\hline Q6 & 38 & 0 \\
\hline Q6/K1 & 72 & 1 \\
\hline Q6/K2 & 82 & 3 \\
\hline Q12 & 50 & 15 \\
\hline Q12/K1 & 82 & 21 \\
\hline Q12/K2 & 90 & 30 \\
\hline
\end{tabular}

compared to the control, was noted in $\mathrm{K} 2$ and $\mathrm{K} 3$ concentrations of the cytostatic drug: in both cases the apoptotic cell nuclei comprised around $80 \%$. The remaining cell nuclei (15-18\%) also demonstrated injuries, which were classified as intermediate ones.

Cell cultures supplemented with Q alone contained around $20 \%$ of typical apoptotic cell nuclei for Q3 and Q6, while for Q12 their number increased to $30 \%$, as compared to the control. In case of intermediate damage of cell nuclei for Q3 comprised the same fraction of apoptotic nuclei $(20 \%$ each, summing up to $40 \%$ of affected cell nuclei). For Q6 the intermediate damage was slightly more frequent, accounting for the total fraction of $50 \%$ affected nuclei. In case of Q12 only $40 \%$ cell nuclei remained without injury, with the intermediate damage comprising $30 \%$.

In comparison with action of DB alone, supplementation with $\mathrm{Q}$ increased the fraction of damaged cell nuclei. In combinations Q with $\mathrm{K} 1$ high levels of intermediate damage could be noted $(80 \%)$. In combinations of Q3/K2, Q6/K2 the fraction of typical apoptotic cells increased (up to $80 \%$ ) as compared to K2. Frequency of intermediate damage was lower than in combinations with $\mathrm{K} 1$.

The combinations DB/Q were more effective than action of $\mathrm{Q}$ alone, particularly a marked increase was noted in the number of apoptotic cell nuclei (Fig. 5).

On the other hand, the TUNEL technique (Table 1) demonstrated that both DB and Q exerted pro-apoptotic effect on cells of the EPP85-181P line. Following

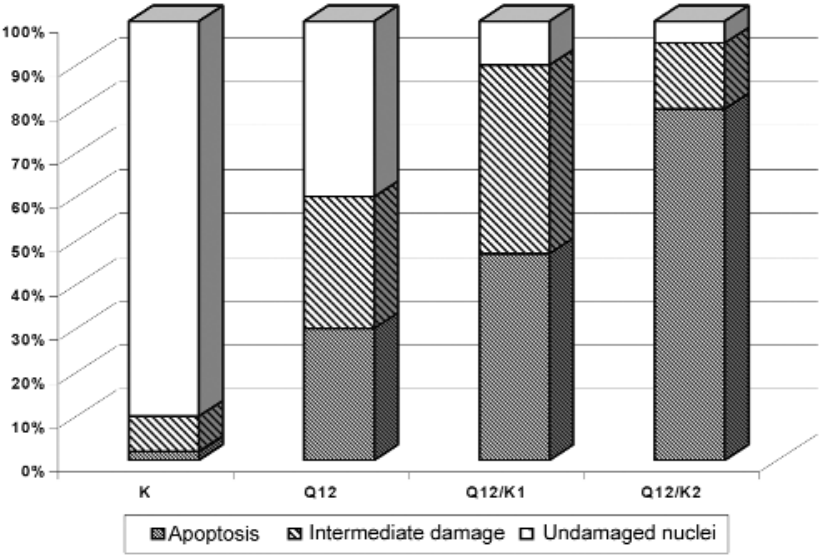

Fig. 5. Effect of Q12 administration and its supplementation with DB on proportion of damaged cell nuclei [\%] in EPP85-181P cell line.

administration of $\mathrm{Q} / \mathrm{DB}$ combinations the action was synergistic. Q intensified effects of DB, particularly in presence of the lowest DB concentration of $\mathrm{K} 1$. Administration of Q12/K1 yielded the same effect as the tenfold higher, therapeutic dose of DB (K2) did. K2 exerted such a high effect alone that supplementation with the polyphenol yielded not so pronounced changes.

EPP85-181RDB line. In the case of resistant cell line of pancreatic carcinoma DB induced apoptotic injury only in a low percentage of cell nuclei, examined using the comet technique.

$\mathrm{Q}$ induced damage in cell nuclei in all applied concentrations. In cases of Q3 and Q6 the fraction of damaged cell nuclei was low (around $6-6.5 \%$ ), but for Q12 it increased to $17 \%$. In every case the intermediate damage was rare. The highest percentage of all damaged cell nuclei, 20\%, was observed for Q12.

Administration of Q/DB combination increased frequency of damaged cell nuclei as compared to action of DB alone. In the cases of combinations with K1 significant alterations and increased number of cell nuclei with intermediate damage in particular could be noted only for Q12/K1. More pronounced differences could be observed in all K2 combinations with Q (Fig. 5).

On the other hand, comparison between influence of $\mathrm{Q}$ concentration alone and combinations $\mathrm{DB} / \mathrm{Q}$ has shown rising fraction of apoptotic cells in the case of suplementation with Q12. The combinations with cytostatic drug significantly augmented frequency of apoptotic changes, particularly of intermediate damage (Table 2).

TUNEL technique (Table 1) demonstrated no significant apoptotic alterations in the resistant cells following administration of DB alone, Q3 or Q6 concentrations or combinations of these polyphenol concentrations with the cytostatic drug. Only in the case of Q12 concentra- 
Table 2. Effect [\%] of various Q and DB combinations on nuclear damage in cells of 85-181RDB cell line, as compared to effect of $\mathrm{Q}$ alone, examined by the comet technique, $\mathrm{C}$ - control.

\begin{tabular}{|l|c|c|c|c|c|c|c|c|c|c|}
\hline \multicolumn{1}{|c|}{ Sample } & $\mathrm{C}$ & $\mathrm{Q} 3$ & $\mathrm{Q} 3 / \mathrm{K} 1$ & $\mathrm{Q} 3 / \mathrm{K} 2$ & $\mathrm{Q} 6$ & $\mathrm{Q} 6 / \mathrm{K} 1$ & $\mathrm{Q} 6 / \mathrm{K} 2$ & $\mathrm{Q} 12$ & $\mathrm{Q} 12 / \mathrm{K} 1$ & $\mathrm{Q} 12 / \mathrm{K} 2$ \\
\hline Apoptosis & 0.3 & 6.5 & 2 & 10 & 6 & 3.5 & 9 & 17 & 18 & 20 \\
\hline Intermadiate damage & 2.9 & 0 & 2 & 2 & 1 & 4.4 & 0 & 3 & 0 & 13 \\
\hline Intact nuclei & 96.8 & 93.5 & 96 & 88 & 93 & 92.1 & 91 & 80 & 82 & 67 \\
\hline
\end{tabular}
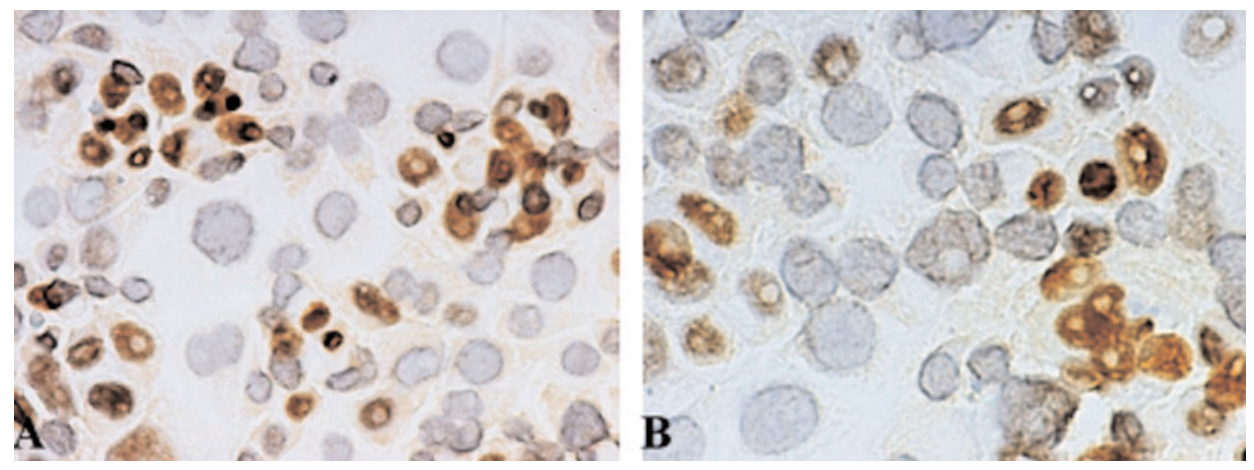

Fig. 6. DNA damage, apoptotic nuclei stained brown. TUNEL technique, original magnification $\times 400$. (A) Cells of EPP85-181RDB line subjected to action of Q12. (B) Cells of EPP85-181RDB line subjected to action of Q12/K1.

tion (Fig. 6A), in combinations of Q12/K1 (Fig. 6B) and Q12/K2 an evident pro-apoptotic effect could be noted.

\section{Discussion}

A flavonol quercetin (Q), the in vitro activity of which on selected neoplastic cell lines provided topic for this study, is commonly present in vegetables and fruits [2]. Two cell lines of human pancreatic cancer, a sensitive and a resistant to $\mathrm{DB}$, provided the cell models.

Tests of cytotoxicity showed that Q inhibits cell divisions in the both studied neoplastic cell lines in a time- and concentration-dependent manner. The subsequent step involved testing if $\mathrm{Q}$ accentuates anti-proliferative effect in the sensitive cell line of human pancreatic carcinoma and if it sensitizes cells to action of a cytostatic drug in the case of the resistant cell line. The experiment was conducted using standard doses of DB, the therapeutic one, the tenfold lower and the tenfold higher one. In the case of Q the priority was to select as low as possible doses, as compared to the commonly used ones, to exclude their possible toxic effect on normal cells. Anti-proliferative action on neoplastic cells of various plant polyphenols including $\mathrm{Q}$ is commonly known and proven $[34,35]$. In parallel, its protective role is stressed in respect to normal cells, related to its antioxidative, anti-inflammatory, cardioprotective, neuroprotective and anti-carcinogenic effects [10,36-39]. It has also been suggested that exists possibility of some toxic effect of $\mathrm{Q}$, even in normal cells, particularly following supplementation of high doses of the flavonol. Therefore, results of studies on its interactions with various drugs seems relatively controversial $[7,13,40,41]$.

Our studies showed that both studied compounds exert effect on the sensitive cell line. Administration of the cytostatic drug alone in its therapeutic dose abolished cell proliferation almost completely. A strong anti-proliferative effect was manifested also by Q alone, particularly its Q6 and Q12 concentrations. Applied together, Q and DB acted synergistically on $P$ cells, which could have been observed on the example of the lowest concentration of K1. The result suggests that in cases of cells sensitive to cytostatics administration of $\mathrm{Q}$ might allow to significantly decrease doses of the drug. This effect might be linked to strong inhibition of topo II by both compounds $[18,42]$. The decrease in therapeutic dose of DB may prove important due to the chance for prevention of negative side effects induced by the drug, assuming that $\mathrm{Q}$ acts selectively: it inhibits proliferation only in neoplastic cells in parallel protecting normal tissues $[13,21,36]$.

In the case of the studied resistant cell line, administration of polyphenol alone significantly inhibited proliferation, particularly in its Q12 concentration. Application of $\mathrm{Q}$ in combination with DB evidently intensified the effect. Most probably, Q sensitizes neoplastic cells resistant to anti-proliferative action of $\mathrm{DB}$ in the manner dependent on Q concentration and, to a slightly lower extent, on dose of the cytostatic drug. The results corroborate data obtained by other investigation centres $[9,43,44]$.

The subsequent step involved examination if the reduced number of cells reflects only more pro- 
nounced inhibition of cell divisions or $\mathrm{Q}$ sensitizes the resistant cells to action of $\mathrm{DB}$, inducing their death by apoptosis and, also, if Q may amplify the effect in cells of pancreatic carcinoma cells line sensitive to DB.

The vast literature devoted to Q shows that it manifests pro-apoptotic properties, as documented in cases of multiple types of tumours [45-47]. Most probably, this involves the late type apoptosis, developing along the mitochondrial pathway, sometimes independent of death receptors (through effects on MAPK, ERK kinases, protein kinase $\mathrm{C}$, proteins of $\mathrm{Bcl}$ family or caspases), which was proven on the example of melanoma cells [48]. Additionally, quercetin augments TRAIL-induced apoptosis by affecting the ERK signal transduction pathway [20]. Q may affect also transcription factors, products of suppressor genes in the cell cycle, e.g. p-53. In cases of mutations in this type regulatory proteins, $\mathrm{Q}$ mobilizes apoptosis along other pathways, independent of p-53 protein, which was documented i.e. for cells of prostate cancer $[9,17,49]$. It is also known that Q may trigger apoptosis in cells of several types of tumours, including pancreatic carcinoma. Additional analysis of apoptosis-linked genes in several of them demonstrated increased expression in presence of as low as $5 \mu \mathrm{M}$ concentration of $\mathrm{Q}$ [7,48-50]. Moreover, $\mathrm{Q}$ does not induce apoptosis in normal cells in concentrations around $10 \mu \mathrm{M}$ and, reciprocally, in such a situation it may protect cells from oxidative stress, inhibit apoptosis and supress neoplastic transformation [13,37,40,51,52].

In case of the sensitive cells, the comet technique proved pro-apoptotic effects of $\mathrm{Q}$ and $\mathrm{DB}$, when applied separately. The tendency persisted in the case of $\mathrm{Q} / \mathrm{DB}$ combination, in which both $\mathrm{Q}$ and $\mathrm{DB}$ concentrations were important. This points to a synergistic effect of the two substances. It should be accentuated that apoptosis was strongly intensified after treatment with Q12 and its combinations with DB (3 and 4 grade according to Yashuara et al.), while the remaining combinations have contained high fraction of intermediate damage (grades 1 and 2 according to Yashuara et al.) [32]. Intensity of apoptosis examined using the TUNEL technique proved slightly lower than that documented by the comet technique but the general tendencies were confirmed.

In the resistant cell line pro-apoptotic effects could have been demonstrated by the comet assay only for Q12 concentration and its combinations with individual doses of DB. On this basis it might be assumed that $\mathrm{Q}$ concentrations lower than $12 \mu \mathrm{M}$ inhibit cell divisions (cell number lower than in the control) but they do not mobilize the apoptotic process. This was also evident that the action of Q12 with combination with $\mathrm{DB}$ is augmented in comparison with the effects of the $\mathrm{Q}$ and DB given separately. These tendencies were confirmed using TUNEL technique.
The above data are consistent with results which suggested that Q it is able to act synergistically with other pro-apoptotic drugs and, in the cases of cells resistant to cytostatic drugs, it may sensitize such cells to action of the cytostatics $[25,50]$.

On the basis of multi-annual studies Q, even in its high concentrations, is known to protect normal cells from toxins and oxidative stress, rather than exert negative side effects $[2,53]$. $\mathrm{Q}$ acts as a strong anti-oxidant in cases of cells such as epithelium of renal tubuli, cardiomyocytes or bone marrow cells and, therefore, it may protect against cardio-, myelo- or nephrotoxicity of the cytostatic drugs, including DB [13,44,53-55]. The described by some research teams mutagenic action of $\mathrm{Q}$ on normal cells was probably linked to administration of very high doses, most frequently exceeding $50 \mu \mathrm{M}$. In cases of low concentrations $(<20 \mu \mathrm{M})$ Q also affects genes but it is not a genotoxic or carcinogenic effect. Analysis of various investigations performed during several years, including in vivo, in vitro and clinical studies, confirmed by detailed analysis of several genes expression, corroborate the thesis [56-58].

Results of our studies confirmed that Q sensitizes cells of human pancreatic carcinoma line resistant to DB. It seems promising for the therapy of tumours manifesting drug resistance. Moreover, Q amplifies action of the cytostatic drug on cells of the sensitive line, which provides perspective for decreasing dosage of the drug. This might be particularly valuable that the synergistic effects of Q and DB in their antiproliferative and pro-apoptotic actions take place only in cases of neoplastic cells, while normal cells in parallel are protected, also against toxic action of cytostatic drugs $[3,16,51]$.

Acknowledgements: This study was supported by MNiSW Grant 1420 (Poland). We would like to thank Dr. H. Lage (Charité University Hospital, Institute of Pathology, Berlin, Germany) for giving us permission to use EPP85-181P and EPP85-181RDB cell lines and Dr. P. Surowiak (Medical University, Dept. of Histology and Embryology, Wroclaw, Poland) for insightful discussion and the gift of some cell culture materials.

\section{References}

[1] Erlund I. Review of flavonoids quercetin, hesperetin, and naringenin. Dietary sources, bioactivities, bioavailability, and epidemiology. Nutr Res. 2004;24:551-874.

[2] Formica JV, Regelson W. Review of the biology of Quercetin and related bioflavonoids. Food Chem Toxicol. 1995;33: 1061-1080.

[3] Bureau G, Longpre F, Martinoli MG. Resveratrol and quercetin, two natural polyphenols, reduce apoptotic neuronal cell death induced by neuroinflammation. J Neurosci Res. 2008;86:403-410.

[4] Nijveldt RJ, van Nood E, van Hoorn DE, Boelens PG, van Norren K, van Leeuwen PA. Flavonoids: a review of probable mechanisms of action and potential applications. Am J Clin Nutr. 2001;74:418-425. 
[ 5] Surh YJ. Cancer chemoprevention with dietary phytochemicals. Nat Rev Cancer. 2003;3:768-780.

[ 6] Yang CS, Landau JM, Huang MT, Newmark HL. Inhibition of carcinogenesis by dietary polyphenolic compounds. Annu Rev Nutr. 2001;21:381-406.

[ 7] van Erk MJ, Roepman P, van der Lende TR et al. Integrated assessment by multiple gene expression analysis of quercetin bioactivity on anticancer-related mechanisms in colon cancer cells in vitro. Eur J Nutr. 2005;44:143-156.

[ 8] Ying B, Yang T, Song X et al. Quercetin inhibits IL-1 betainduced ICAM-1 expression in pulmonary epithelial cell line A549 through the MAPK pathways. Mol Biol Rep. 2008;36: 1825-1832.

[9] Choi EJ, Bae SM, Ahn WS. Antiproliferative effects of quercetin through cell cycle arrest and apoptosis in human breast cancer MDA-MB-453 cells. Arch Pharm Res. 2008;31:1281-1285.

[10] Zamin LL, Filippi-Chiela EC, Dillenburg-Pilla P, Horn F, Salbego C, Lenz G. Resveratrol and quercetin cooperate to induce senescence-like growth arrest in C6 rat glioma cells. Cancer Sci.. 2009;100:1655-1662.

[11] Xavier CP, Lima CF, Preto A, Seruca R, Fernandes-Ferreira $\mathrm{M}$, Pereira-Wilson C. Luteolin, quercetin and ursolic acid are potent inhibitors of proliferation and inducers of apoptosis in both KRAS and BRAF mutated human colorectal cancer cells. Cancer Lett. 2009;281:162-170.

[12] Liesveld JL, Abboud CN, Lu C et al. Flavonoid effects on normal and leukemic cells. Leuk Res. 2003;27:517-527.

[13] Son YO, Lee KY, Kook SH et al. Selective effects of quercetin on the cell growth and antioxidant defense system in normal versus transformed mouse hepatic cell lines. Eur $J$ Pharmacol. 2004;502:195-204.

[14] Binaschi M, Capranico G, Dal Bo L, Zunino F. Relationship between lethal effects and topoisomerase II-mediated doublestranded DNA breaks produced by anthracyclines with different sequence specificity. Mol Pharmacol. 1997;51:1053-1059.

[15] Cortes-Funes H, Coronado C. Role of anthracyclines in the era of targeted therapy. Cardiovasc Toxicol. 2007;7:56-60.

[16] Bast A, Haenen GR, Bruynzeel AM, Van der Vijgh WJ. Protection by flavonoids against anthracycline cardiotoxicity: from chemistry to clinical trials. Cardiovasc Toxicol. 2007;7:154-159.

[17] Le Good JA, Ziegler WH, Parekh DB, Alessi DR, Cohen P, Parker PJ. Protein kinase C isotypes controlled by phosphoinositide 3-kinase through the protein kinase PDK1. Science. 1998;281:2042-2045.

[18] Nguyen TT, Tran E, Nguyen TH, Do PT, Huynh TH, Huynh $H$. The role of activated MEK-ERK pathway in quercetininduced growth inhibition and apoptosis in A549 lung cancer cells. Carcinogenesis. 2004;25:647-659.

[19] Warren CA, Paulhill KJ, Davidson LA et al. Quercetin may suppress rat aberrant crypt foci formation by suppressing inflammatory mediators that influence proliferation and apoptosis. J Nutr. 2009;139:101-105.

[20] Kim YH, Lee DH, Jeong JH, Guo ZS, Lee YJ. Quercetin augments TRAIL-induced apoptotic death: involvement of the ERK signal transduction pathway. Biochem Pharmacol. 2008;75:1946-1958.

[21] Kim EJ, Choi CH, Park JY, Kang SK, Kim YK. Underlying mechanism of quercetin-induced cell death in human glioma cells. Neurochem Res. 2008;33:971-979.

[22] Robert J. Williams JPES, Catherine Rice-Evans. Flavonoids: antioxidants or signalling molecules? Free Radic Biol Med. 2004;37:838-849.

[23] Ghosh A, Mandal AK, Sarkar S, Panda S, Das N. Nanoencapsulation of quercetin enhances its dietary efficacy in combating arsenic-induced oxidative damage in liver and brain of rats. Life Sci. 2009;84:75-80.
[24] Gupta C, Vikram A, Tripathi DN, Ramarao P, Jena GB: Antioxidant and antimutagenic effect of quercetin against DEN induced hepatotoxicity in rat. Phytother Res. 2009;24:119-128.

[25] Borska S, Gebarowska E, Wysocka T, Drag-Zalesinska M, Zabel M. The effects of quercetin vs cisplatin on proliferation and the apoptotic process in A549 and SW1271 cell lines in in vitro conditions. Folia Morphol (Warsz). 2004;63:103-105.

[26] Di Pietro A, Conseil G, Perez-Victoria JM et al. Modulation by flavonoids of cell multidrug resistance mediated by P-glycoprotein and related ABC transporters. Cell Mol Life Sci. 2002;59:307-322.

[27] Kioka N, Hosokawa N, Komano T, Hirayoshi K, Nagata K, Ueda K. Quercetin, a bioflavonoid, inhibits the increase of human multidrug resistance gene (MDR1) expression caused by arsenite. FEBS Lett. 1992;301:307-309.

[28] Ozben T. Mechanisms and strategies to overcome multiple drug resistance in cancer. FEBS Lett. 2006;580:2903-2909.

[29] Saczko J, Kulbacka J, Chwilkowska et al. Cytosolic superoxide dismutase activity after photodynamic therapy, intracellular distribution of Photofrin II and hypericin, and P-glycoprotein localization in human colon adenocarcinoma. Folia Histochem Cytobiol. 2007;45:93-98.

[30] Lage H, Jordan A, Scholz R, Dietel M. Thermosensitivity of multidrug-resistant human gastric and pancreatic carcinoma cells. Int J Hyperthermia. 2000;16:291-303.

[31] Skehan P, Storeng R, Scudiero D et al. New colorimetric cytotoxicity assay for anticancer-drug screening. J Natl Cancer Inst. 1990;82:1107-1112.

[32] Yasuhara S, Zhu Y, Matsui T. Comparison of comet assay, electron microscopy, and flow cytometry for detection of apoptosis. J Histochem Cytochem. 2003;51:873-885.

[33] Cerda H, Delincee H, Haine H, Rupp H. The DNA 'comet assay' as a rapid screening technique to control irradiated food. Mutat Res. 1997;375:167-181.

[34] Borska S, Gebarowska E, Wysocka T, Drag-Zalesinska M, Zabel M. Induction of apoptosis by EGCG in selected tumour cell lines in vitro. Folia Histochem Cytobiol. 2003;41:229-232.

[35] Shan BE, Wang MX, Li RQ. Quercetin inhibit human SW480 colon cancer growth in association with inhibition of cyclin D1 and survivin expression through $\mathrm{Wnt} /$ beta-catenin signaling pathway. Cancer Invest. 2009;27:604-612.

[36] Ansari MA, Abdul HM, Joshi G, Opii WO, Butterfield DA. Protective effect of quercetin in primary neurons against Abeta(1-42): relevance to Alzheimer's disease. $J$ Nutr Biochem. 2009;20:269-275.

[37] Lee KW, Kang NJ, Heo YS et al. Raf and MEK protein kinases are direct molecular targets for the chemopreventive effect of quercetin, a major flavonol in red wine. Cancer Res. 2008;68:946-955.

[38] Chao CL, Hou YC, Chao PD, Weng CS, Ho FM. The antioxidant effects of quercetin metabolites on the prevention of high glucose-induced apoptosis of human umbilical vein endothelial cells. Br J Nutr. 2009;101:1165-1170.

[39] Jagtap S, Meganathan K, Wagh V, Winkler J, Hescheler J, Sachinidis A. Chemoprotective mechanism of the natural compounds, epigallocatechin-3-O-gallate, quercetin and curcumin against cancer and cardiovascular diseases. Curr Med Chem. 2009;16:1451-1462.

[40] Johnson MK, Loo G. Effects of epigallocatechin gallate and quercetin on oxidative damage to cellular DNA. Mutat Res. 2000;459:211-218.

[41] Morrow DM, Fitzsimmons PE, Chopra M, McGlynn H. Dietary supplementation with the anti-tumour promoter quercetin: its effects on matrix metalloproteinase gene regulation. Mutat Res. 2001;480-481:269-276.

[42] Szulawska A, Czyz M: [Molecular mechanisms of anthracyclines action]. Postepy Hig Med Dosw. 2006;60:78-100. 
[43] O'Leary KA, de Pascual-Tereasa S, Needs PW, Bao YP, O'Brien NM, Williamson G. Effect of flavonoids and vitamin E on cyclooxygenase-2 (COX-2) transcription. Mutat Res. 2004;551:245-254.

[44] Ross JA, Kasum CM. Dietary flavonoids: bioavailability, metabolic effects, and safety. Annu Rev Nutr. 2002;22:19-34.

[45] Choi YJ, Jeong YJ, Lee YJ, Kwon HM, Kang YH. (-)Epigallocatechin gallate and quercetin enhance survival signaling in response to oxidant-induced human endothelial apoptosis. J Nutr. 2005;135:707-713.

[46] Aalinkeel R, Bindukumar B, Reynolds JL et al. The dietary bioflavonoid, quercetin, selectively induces apoptosis of prostate cancer cells by down-regulating the expression of heat shock protein 90. Prostate 2008;68:1773-1789.

[47] Kim JY, Kim EH, Park SS, Lim JH, Kwon TK, Choi KS. Quercetin sensitizes human hepatoma cells to TRAILinduced apoptosis via Sp1-mediated DR5 up-regulation and proteasome-mediated c-FLIPS down-regulation. $J$ Cell Biochem. 2008;105:1386-1398.

[48] Rosner K, Ropke C, Pless V, Skovgaard GL. Late type apoptosis and apoptosis free lethal effect of quercetin in human melanoma. Biosci Biotechnol Biochem. 2006;70:2169-2177.

[49] Vijayababu MR, Arunkumar A, Kanagaraj P, Arunakaran J. Effects of quercetin on insulin-like growth factors (IGFs) and their binding protein-3 (IGFBP-3) secretion and induction of apoptosis in human prostate cancer cells. $J$ Carcinog. 2006;5:10.

[50] Mertens-Talcott SU, Percival SS. Ellagic acid and quercetin interact synergistically with resveratrol in the induction of apoptosis and cause transient cell cycle arrest in human leukemia cells. Cancer Lett. 2005;218:141-151.
[51] Kaindl U, Eyberg I, Rohr-Udilova N, Heinzle C, Marian B. The dietary antioxidants resveratrol and quercetin protect cells from exogenous pro-oxidative damage. Food Chem Toxicol. 2008;46:1320-1326.

[52] Kimura S, Warabi E, Yanagawa T et al. Essential role of Nrf2 in keratinocyte protection from UVA by quercetin. Biochem Biophys Res Commun. 2009.

[53] Miura T, Muraoka S, Fujimoto Y. Inactivation of creatine kinase induced by quercetin with horseradish peroxidase and hydrogen peroxide. pro-oxidative and anti-oxidative actions of quercetin. Food Chem Toxicol. 2003;41:759-765.

[54] Moon YJ, Wang X, Morris ME. Dietary flavonoids: effects on xenobiotic and carcinogen metabolism. Toxicol in vitro. 2006;20:187-210

[55] O'Prey J, Brown J, Fleming J, Harrison PR. Effects of dietary flavonoids on major signal transduction pathways in human epithelial cells. Biochem Pharmacol. 2003;66:2075-2088.

[56] Dunnick JK, Hailey JR. Toxicity and carcinogenicity studies of quercetin, a natural component of foods. Fundam Appl Toxicol. 1992;19:423-431.

[57] Harwood M, Danielewska-Nikiel B, Borzelleca JF, Flamm GW, Williams GM, Lines TC. A critical review of the data related to the safety of quercetin and lack of evidence of in vivo toxicity, including lack of genotoxic/carcinogenic properties. Food Chem Toxicol. 2007;45:2179-2205.

[58] Okamoto T: Safety of quercetin for clinical application (Review). Int J Mol Med. 2005;16:275-278.

Submitted: 1 August, 2009 Accepted after revision: 31 January, 2010 